\title{
BUDAYA BAHARI MASYARAKAT SRIWIJAYA PADA MASA PRA-MODERN
}

\author{
Yopi Rachmad \\ Guru Sejarah SMA Negeri 6 Binjai, Sumatera Utara, Indonesia \\ Email: yopismantig@gmail.com
}

\begin{abstract}
This article discusses the nautical culture of the Srivijaya community in pre-modern times. Narratives are built through a re-reading of scientific studies that review the archaeological findings originating from the Kingdom of Srivijaya. The archaeological findings were then analyzed using the human ecological theory of culture. This study shows that the Srivijaya people made the sea as a source of connecting life. The production orientation of the community such as fishing, local handicrafts, and other maritime expertise is for commodity trading in the main ports of the Srivijaya kingdom. Trade era has changed Southeast Asia and allowed it to become a global power in its time. This can be seen by the discovery of pictures of ships in temple reliefs and various archaeological findings. One of the skills that must be possessed by the community is expertise in shipbuilding. Ships made are used for various maritime facilities, both as a means of transportation between regions and between continents and also as a commodity sold in ports.
\end{abstract}

Keywords: Human Ecology, Maritime Culture, Maritime Society, Srivijaya

\begin{abstract}
Abstrak
Artikel ini membahas tentang kebudayaan bahari masyarakat Sriwijaya pada masa pra-modern. Narasi dibangun melalui pembacaan ulang terhadap kajian-kajian ilmiah yang mengulas tentang temuan-temuan arkeologis yang berasal dari Kerajaan Sriwijaya. Temuan-temuan arkeologis itu kemudian dianalisis dengan menggunakan teori ekologi manusia dari ilmu budaya. Kajian ini menunjukkan bahwa masyarakat Sriwijaya menjadikan laut sebagai sumber dalam menyambung kehidupan. Orientasi produksi masyarakatnya seperti menangkap ikan, kerajinan lokal dan keahlian maritim lainnya adalah untuk komoditas perdagangan di pelabuhan-pelabuhan utama kerajaan Sriwijaya. Kurun niaga telah mengubah Asia Tenggara dan memungkinkannya menjadi sebuah kekuatan global pada masanya. Hal ini dapat dilihat dengan ditemukannya gambar kapal pada relief-relief candi dan berbagai temuan arkeologis. Salah satu keahlian yang harus dimiliki masyarakat adalah keahlian dalam membuat kapal. Kapal-kapal yang dibuat digunakan untuk berbagai sarana kemaritiman, baik sebagai alat transportasi antar kawasan maupun antar benua dan juga sebagai komoditi yang dijual di pelabuhan-pelabuhan.
\end{abstract}

Kata Kunci: Ekologi Manusia, Budaya Bahari, Masyarakat Maritim, Sriwijaya 


\section{PENDAHULUAN}

Sriwijaya merupakan nama dari sebuah kerajaan yang dikenal sebagai Kerajaan Nusantara I (satu). Hal ini karena wilayah kekuasaannya disebut-sebut meliputi wilayah Nusantara saat ini, bahkan lebih besar dari itu. Kerajaan Sriwijaya merupakan kerajaan bahari yang pernah berdiri di Nusantara. Penelitian tentang kerajaan ini dimulai sejak tahun 1918 oleh Coedes (1975) dengan menganalisis sumber berita Cina. Dalam perkembangan selanjutnya, penelitian tentang Sriwijaya semakin berkembang dengan mencoba membaca berbagai temuan arkeologis di Kota Palembang. Satu hal yang menarik adalah bahwa kerajaan ini merupakan salah satu kerajaan tertua dan terbesar yang pernah hadir secara politis di Nusantara, namun kerjaan ini juga merupakan kerajaan termuda jika dikaitkan dengan penemuannya apabila dibandingkan dengan kerajaan-kerajaan yang pernah ada di pulau Jawa.

Sebagaimana yang telah disebutkan di atas, penelitian dan penemuan Sriwijaya baru dimulai pada abad ke 20 oleh Coedes (1975) sehingga terbilang masih "kerajaan termuda" di Nusantara. Hal ini menggambarkan bahwa penelitian tentang Sriwijaya masih belum benarbenar massif dilakukan. Penelitian tentang Sriwijaya baru dimulai secara massif melalui program-program nasional Pusat Penelitian Arkeologi Nasional sejak tahun 1970. Pemerintah mulai mempunyai perhatian besar atas situs-situs Sriwijaya di Sumatera dan mengadakan survei serta ekskavasi di Palembang. Penelitian yang dilakukan pada tahun 1974 oleh Pusat Penelitian Arkeologi Nasional dengan University of Pennsylvania yang diwakili Dr. Bennet Bronson melakukan ekskavasi di sekitar Ki Gede Ing Suro dengan hasil yang belum begitu memuaskan. Pada tahun 1979, South East Asia Menister of Education (SEAMEO) Project on a Chaeology and Fine Art (SPAFA) bersama Pusat Penelitian Arkeologi Nasional menyelenggarakan lokakarya khusus tentang Sriwijaya. Dalam pertemuan itu para ahli arkeologi Asia
Tenggara dan para pakar dari luar kawasan Asia Tenggara membahas masalah Sriwijaya. Pertemuan serupa kembali diselenggarakan pada tahun 1982. Hasil pertemuan itu memperkuat Palembang sebagai ibukota awal Sriwijaya.

Namun, hasil penelitian yang telah dilakukan tentang Kerajaan Sriwijaya belum begitu mampu menghadirkan analisis yang dapat menggambarkan kondisi masyarakat Sriwijaya pada masanya. Fokus yang dibicarakan oleh sebagian besar kajian tentang Sriwijaya hanya berkutat pada penentuan letak ibu kota Sriwijaya dan sosialisasi temuan-temuan arkeologis yang diperoleh. Demikian pula dengan hasil penelitian Gaynor (2012) yang lebih banyak mengungkapkan bahwa pada masa Sriwijaya terdapat banyak bajak laut di sekitar perairan Sriwijaya. Penelitian yang menggali lebih banyak keterangan mengenai kondisi masyarakat Kerajaan Sriwijaya masih jarang dilakukan. Oleh karena itu, patut dilakukan penelitian lanjutan dengan melakukan pembacaan ulang terhadap tinggalantinggalan arkeologis sehingga sejarah Sriwijaya yang merupakan kerajaan maritim di Nusantara menjadi utuh, tidak seperti puzzle yang terserak

Kajian ini akan mencoba melakukan pembacaan ulang terhadap peninggalan-peninggalan Kerajaan Sriwijaya dengan menggunakan pendekatan yang berbeda dari penelitian yang pernah ada. Kajian ini berfokus pada perkembangan budaya bahari masyarakat Sriwijaya di masa pra-modern. Untuk membantu memahami kebudayaan bahari masyarakat Sriwijaya, kajian ini menggunakan teori ekologi manusia dari ilmu budaya. Teori ekologi manusia atau ekologi budaya dipelopori oleh seorang sarjana Amerika Utara yang bernama Julian Steward (19021972). Ia adalah orang pertama yang memasukkan kajian tentang hubungan antara budaya dengan lingkungan ke dalam bidang kajian ekologis (Bennet, 1976: 2). Namun, embrio dari pemikiran itu berasal dari pengaruh aliran pemikiran "partikularisme historis" Frans Boaz (Orlove, 1980: 237). 
Cara pandang teori ekologi manusia berbeda dengan teori determinisme lingkungan. Teori determinisme lingkungan memposisikan lingkungan alam sebagai suatu faktor yang menentukan terhadap budaya. Perbedaan budaya terjadi karena perbedaan lingkungan alam di mana budaya itu hidup. Sementara itu, teori ekologi manusia lebih menekankan peranan eksploitasi lingkungan alam oleh manusia melalui medium budaya yang dimilikinya dan penyesuaian kehidupan manusia terhadap kondisikondisi suatu lingkungan alam. Jadi, teori determinisme lingkungan cenderung me-lihat hubungan lingkungan alam dengan budaya sebagai hubungan kausal yang lenier, sebaliknya teori ekologi budaya melihat hubungan tersebut dalam bentuk dialektikal.

Teori determinisme percaya bahwa kemanusiaan dan budaya ditentukan oleh bentukbentuk lingkungan alam, dan bahwa fenomena kebudayaan dapat dijelaskan dan seharusnya diramalkan melalui dasar kerangka acuan kepada lingkungan alam di mana mereka tinggal (Vayda \& Rappaport, 1968: 8). Namun, teori ekologi manusia percaya bahwa tidak semua kebudayaan manusia ditentukan oleh lingkungan. Oleh karenanya, kajian ini memandang kebudayaan sebagai sistem adaptif dari keyakinan perilaku yang fungsi primernya adalah menyesuaikan diri dengan lingkungan fisik dan sosialnya. Pendekatan ini dikaitkan dengan ekologi budaya dan materialisme kebudayaan, serta bisa ditemukan dalam kajian antropolog Steward (1955), White (1949, 1959) dan Harris (1968, 1979).

Dengan menggunakan teori ekologi manusia sebagai kerangka berpikir, maka kajian ini diharapkan dapat mengungkap tradisi bahari yang berkembang dalam masyarakat Sriwijaya. Selain itu, kajian ini juga diharapkan dapat mengidentifikasi hasil-hasil kebudayaan bahari masyarakat Sriwijaya.

\section{METODE PENELITIAN}

Tulisan ini merupakan kajian sejarah tentang budaya bahari masyarakat Sriwijaya pada masa pra-modern. Sumber yang digunakan adalah sumber tertulis berupa buku, jurnal dan laporan penelitian yang memuat temuan-temuan arkeologis yang berasal dari Kerajaan Sriwijaya. Narasi dibangun berdasarkan pembacaan ulang terhadap tinggalan-tinggalan arkeologis dari Kerajaan Sriwijaya dengan menggunakan teori ekologi manusia dari ilmu budaya untuk melacak kebudayaan bahari masyarakat Sriwijaya.

\section{HASIL DAN PEMBAHASAN}

Fenomena sosial budaya begitu kompleks, terutama berkaitan dengan kelompok dan kategori sosial, baik yang terlibat secara langsung atau tidak langsung dalam pemanfaatan sumberdaya dan lingkungan, serta beragamnya sektor mata pencaharian terkait perairan baik laut maupun sungai, sehingga menjadi alasan lebih tepat menggunakan terminologi "budaya bahari" daripada terminologi "budaya maritim" dan "budaya marin" dalam rangka pengkajian ilmiah.

Untuk mendeskripsikan dan menganalisis fenomena budaya bahari yang kompleks, kiranya cukup memadai bila digunakan konsep "tiga wujud kebudayaan" (sistem gagasan, sistem sosial dan budaya material) yang dikemukakan Koentjaraningrat (1980) daripada melakukan reduksi wujud kedua dan ketiga seperti dilakukan para antropolog kognitif (Goodenough, 1994) dan simbolik (Geertz, 1973) atau secara berlebihan menekankan pada pertimbangan rasional biaya dan keuntungan (cost-benefit considerations) seperti dilakukan para penganut materialisme budaya (Harris, 1968: 19). Defenisi kebudayaan yang secara jelas mencakup ketiga wujud tersebut dikemukakan oleh Koentjaraningrat, (1980: 193), bahwa kebudayaan merupakan keseluruhan sistem gagasan, tindakan dan hasil karya manusia dalam rangka kehidupan yang dijadikan milik diri manusia dengan belajar. 
Di dalam kebudayaan Indonesia, para pakar sejarah maritim menduga bahwa perahu telah lama memainkan peranan penting di wilayah nusantara, jauh sebelum bukti tertulis menyebutkannya (prasasti dan naskah-naskah kuno). Dugaan ini didasarkan atas sebaran berbagai artefak, seperti nekara, kapak dan bejana perunggu yang ditemukan di berbagai tempat di Sumatera, Sulawesi, Papua hingga Rote. Berdasarkan bukti-bukti tersebut, pada masa akhir prasejarah telah dikenal adanya jaringan perdagangan antara Nusantara dan bangsa-bangsa lain di dunia.

Jika kita bandingkan, hal yang sama juga terjadi pada Kerajaan Haru di Sumatera Timur. Temuan-temuan arkeologis itu menggambarkan kondisi budaya bahari. Demikian pula dengan Sriwijaya. Jika kita merujuk pada temuantemuan arkeologis tersebut, maka tampak jelas bahwa Sumatera secara terus-menerus melakukan hubungan perdagangan dengan bangsabangsa asing. Pelabuhan-pelabuhan penting muncul sebagai akibat dari interaksi ekonomi maupun budaya dengan bangsa asing, sehingga tidak juga benar bahwa hanya Jawa saja yang menjadi pusat perdagangan internasonal di Asia Tenggara (Rachmad, 2017: 43).

Salah satu prasasti yang menjelaskan tentang Kerajaan Sriwijaya adalah Prasasti Kedukan Bukit berangka tahun 604 Saka (682 M), yang merupakan prasasti berangka tahun tertua di Indonesia. Prasasti ini telah disebutkan dalam penelitian Manguin (2008) yang membahas tentang identitas Sriwijaya. Demikian juga Zakharov (2009) yang melakukan analisis politik kerajaan Sriwijaya. Di dalam sebahagian prasasti tersebut berisi:

...(1) bahagia! Pada tahun Saka 605 hari kesebelas, (2) dari bulan terang bulan waisakha dapunta hyang naik (3) di perahu melakukan shiddhayatra. Pada hari ketujuh bulan terang (4) bulan jyetsha dapunta hyang berangkat dari minanga (5) tma membawa tentara dua laksa orang (6) dua ratus orang di perahu yang berjalan seribu (7) 312 banyaknya datang di matada... (8) dengan senang hati pada hari kelima dari terang bulan (asada) (9) dengan lega gembira datang membuat wanua (10) Sriwijaya melakukan perjalanan dengan lengkap... (Nilakanta-Sastri, 1949).

Dari cuplikan kalimat prasasti di atas tergambar dengan jelas bahwa Dapunta Hyang melakukan perjalanan pada tahun 605 hari ke sebelas. Perjalanan itu menggunakan perahu karena pada kalimat "(3) di perahu melakukan shiddhayatra" yang berarti perjalanan suci. Melalui kalimat itu dapat digambarkan bahwa di masa itu perjalanan dilakukan dengan menggunakan perahu untuk menjangkau satu wilayah ke wilayah lainnya. Hal ini memperlihatkan bahwa perahu sudah digunakan pada sekitar abad ke 7 Masehi. Hal ini merupakan bagian dari budaya bahari yang menjadi gambaran budaya masyarakat Sriwijaya. Dengan memperhatian kondisi alam dan luasnya wilayah Sriwijaya, maka patut diduga bahwa kondisi tersebut membuat Sriwijaya berusaha untuk menjangkau semua wilayah kekuasaannya melalui kebudayaan yang dihasilkan, yaitu kebudayaan bahari.

Jika kita merunut apa yang disampaikan oleh Mahan (1989), negara maritim atau pada waktu itu berbentuk kerajaan maritim merupakan negara atau kerajaan yang memiliki visi atau pandangan hidup maritim untuk memanfaatkan dan mengontrol laut sebagai syarat mutlak untuk mencapai kesejahteraan dan kejayaan. Menurut Mahan (1989) ada enam syarat sebuah negara maritim, yakni lokasi geografis, karakteristik tanah dan pantai, luas wilayah, jumlah penduduk, karakter penduduk dan pemerintahan. Negara maritim harus dapat mengendalikan pulau-pulau yang menjadi daerah kekuasaannya. Untuk itu, negara maritim harus memiliki armada laut yang tangguh, baik armada perang maupun armada dagang. 
Balai Arkeologi Palembang menemukan sebuah perahu kuno yang diperkirakan ada sejak masa awal Kerajaan Sriwijaya di Desa Sungai Pasir, Kecamatan Cengal, Kabupaten Ogan Komering Ilir, Sumatera Selatan. Sayangnya, kepala perahu kuno itu sudah hilang dan sebagian papan perahu itu digunakan buat jembatan. Tercatat ada 17 keping perahu yang terdiri dari bagian lunas, 14 papan perahu yang terdiri dari bagian badan dan bagian buritan untuk menempatkan kemudi. Perahu ini dibuat dengan teknik pasak kayu dan papan ikat yang menggunakan tali ijuk. Cara ini sendiri dikenal dengan sebutan teknik tradisi Asia Tenggara. Selain bangkai perahu, ditemukan juga sejumlah artefak-artefak lain yang berhubungan dengan temuan perahu, seperti tembikar, keramik dan alat kayu.

Sesuai dengan sistem transportasi pada masa itu yang masih bertumpu pada jalur sungai, dapat kita pastikan bahwa bandar-bandar perdagangan yang sering berfungsi sebagai pusat sebuah kekuasaan politik (kerajaan) pastilah berada di sekitar muara sungai. Palembang yang disebut sebagai ibu kota Sriwijaya merupakan sebuah kota yang berada di bantaran Sungai Musi, di mana lebar sungai tersebut sama dengan Sungai Thames dan Greenwich. Penduduk asli Palembang adalah orang Melayu (Wallace, 2009: 89). Palembang yang juga pernah menjadi pusat penyebaran agama Buddha di Nusantara ramai didatangi bangsa-bangsa asing untuk melakukan perdagangan dan bahkan menetap di pinggiran Sungai Musi. Di tepian Sungai Musi terdapat barisan rumah yang dibangun di atas rakit bambu berukuran besar yang dihubungkan dengan mengunakan tali yang diikatkan pada sisi sungai atau pada tiang (Nurhayati, 2016: 11). Dengan kondisi demikian, masyarakat mulai menyesuaikan diri dengan pola kehidupan di bantaran Sungai Musi. Mereka beradaptasi untuk dapat bertahan hidup. Melalui pendekatan ekologi manusia atau ekologi kebudayaan dapat dijelaskan bahwa lingkungan alam dan sosial dengan manusianya sebagai pencipta kebudayaan melakukan dialektika yang terus- menerus sehingga menghasilkan kebudayaan bahari tersebut.

Masyarakat kemungkinan sedikit sekali menggunakan waktu dan kekayaannya untuk rumah mereka. Kondisi alam dan tersedianya pohon-pohon yang cepat besar, pohon kelapa dan bambu sebagai bahan bangunan rumah menjadi penyebab utama dari rendahnya prioritas ini. Biaya untuk membangun rumah cukup murah. Rumah dianggap sebagai sesuatu yang tidak permanen dan bukan sarana yang patut untuk menanam uang.

Kondisi ini sama dengan persepsi masyarakat di Asia Tenggara lainnya. Bahan bangunan mudah didapat dan juga mudah hancur. Atap ilalang dan lantai bilah bambu harus diganti setelah sepuluh tahun. Tiang rumah berada di atas tanah. Bentuknya rumah panggung sederhana. Tiang-tiang penyangga diikatkan satu sama lain sehingga kokoh karena sangat mempengaruhi struktur tengah bangunan rumah. Hal ini menjaga mereka dari pasang naik air laut. Rumah-rumah menggunakan tangga sebagai pintu masuk. Itulah mengapa kemudian muncul istilah melayu, "rumah tangga" dalam kehidupan sehari-sehari hingga saat ini.

Meskipun terdapat ahli bangun rumah dan tukang kayu, keahlian dasar untuk membangun rumah dimiliki oleh masyarakat secara luas sehingga hampir setiap orang adalah tukang kayu. Keluarga besar saling membantu dalam membangun rumah sehingga rumah dapat selesai dalam beberapa hari.

Tinggi rumah sangat beragam, walaupun tinggi lantainya secara umum adalah antara satu hingga tiga meter. Namun yang berbeda adalah untuk rumah raja dan bangsawan. Tinggi rumah bisa hingga dua belas meter (Reid, 2014: 72). Hal ini menggambarkan bahwa rumah raja dan bangsawan harus lebih tinggi daripada rumah masyarakat kebanyakan.

Salah satu keahlian yang harus dimiliki masyarakat adalah keahlian dalam membuat kapal. Kapal-kapal yang dibuat digunakan untuk berbagai sarana bahari, baik sebagai alat trans- 
portasi antarkawasan maupun antarbenua dan juga sebagai komoditi yang dijual di pelabuhanpelabuhan.

Rachmad (2017: 79) menjelaskan bahwa sudah banyak penelitian tentang budaya bahari Bugis Makassar yang ditulis oleh para penulis sejarah maritim, sehingga narasi ceritanya bersambung hingga saat ini. Kita akan melihat gambaran yang utuh bagaimana budaya ini diturunkan secara turun temurun sehingga Pelly (1975) menyebutkan bahwa keahlian orangorang Bugis di desa Ara sama tuanya dengan kebudayaan maritim suku bugis Makassar itu sendiri. Demikian Zuhdi (2014) yang menjelaskan tentang budaya maritim orang Buton. Walaupun orang Kampai juga percaya bahwa keahlian mereka diturunkan secara turuntemurun, dari generasi ke generasi.

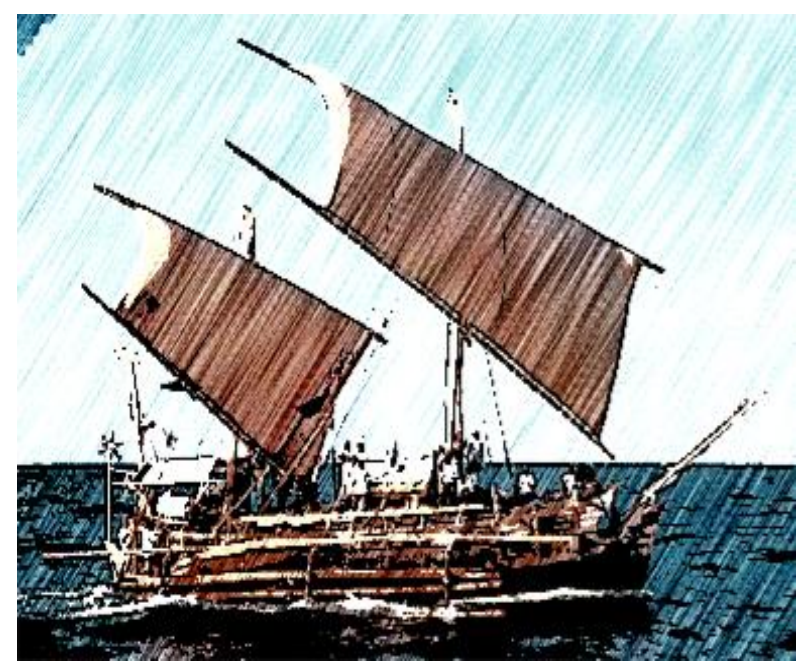

Gambar 1. Perahu Tradisional Melayu

Salah satu catatan Kerajaan Wu (Abad ke-3 Masehi) menceritakan adanya kapal Kun Lun Po, sebutan perahu pelaut Nusantara. Perahu besar ini panjangnya hingga 200 kaki (lebih kurang 61 Meter), tinggi dari muka air 20-30 kaki (lebih kurang 9 Meter), serta mampu memuat 600 orang dan barang 10.000 ho (setara dengan 10 sekop jagung), dengan empat layar dipasang di perahu. Layar kapal terbuat dari anyaman tanaman agar mudah digerakkan sesuai arah angin sehingga perahu dapat melaju dengan lincah.

Gambaran ini melebihi kapal yang digunakan para penjelajah asing, bahkan oleh Colombus yang berisikan hanya 88 awak kapal. Sangat kecil apabila dibandingkan dengan kapal Kun Lun Po tersebut. Hal ini juga menjawab hipotesa yang selama ini ada bahwa perdagangan yang terdapat di Asia Tenggara baru ramai sehingga terjadi perubahan struktur perdagangan setelah kedatangan bangsa Barat ke Asia Tenggara. Bahkan menurut sumber Portugis, perubahan tersebut sudah terjadi ketika Portugis menduduki Malaka pada 1511.

\section{SIMPULAN}

Dari hasil penulusuran sejumlah sumber tertulis yang dianalisis berdasarkan teori ekologi manusia atau ekologi budaya dapat disimpulkan bahwa kondisi geografis Kerajaan Sriwijaya turut mempengaruhi perkembangannya menjadi sebuah kerajaan maritim yang sangat disegani di Selat Malaka. Dengan kondisi demikian, masyarakatnya beradaptasi dengan lingkungannya untuk mengeksploitasi sumber-sumber alam maritim.

Sebagai sebuah kerajaan maritim, penduduk kerajaan Sriwijaya juga merupakan masyarakat maritim. Mereka menjadikan laut sebagai sumber dalam menyambung kehidupan. Orientasi produksi masyarakatnya seperti menangkap ikan, kerajinan lokal dan keahlian maritim lainnya adalah untuk komoditas perdagangan di pelabuhan-pelabuhan utama Kerajaan Sriwijaya.

Kurun niaga (trade of era) telah mengubah Asia Tenggara dan memungkinkan dearah ini menjadi sebuah kekuatan global pada masanya. Hal ini dapat dilihat dengan ditemukannya gambar kapal pada relief-relief candi dan berbagai temuan arkeologis. Salah satu keahlian yang harus dimiliki masyarakat adalah keahlian dalam membuat kapal. Kapal-kapal yang dibuat digunakan untuk berbagai sarana kemaritiman, baik sebagai alat transportasi antarkawasan 
maupun antarbenua dan juga sebagai komoditi yang dijual di pelabuhan-pelabuhan.

Sebagai penutup, perlu kiranya dilakukan penelitian lebih lanjut tentang sejarah kebudayaan bahari masyarakat Indonesia dengan menggunakan pendekatan ilmu budaya maupun ilmu sosial sehingga kajian sejarah maritim di Indonesia dapat disusun secara utuh. Dengan penelitian lebih mendalam, gambaran potensi bahari Indonesia dapat dikelola untuk kemajuan bangsa di masa-masa yang akan datang.

\section{REFERENSI}

Bennet, J. W. (1976). Human Ecology as Human Behavior. New Jersey: Transaction Publishers.

Coedes, G. (1975). The Indianized State of Southeast Asia. Canberra: ANU Press.

Gaynor, J. L. (2012). Piracy in the Offing: The Law of Lands and the Limits of Sovereignty at Sea. Anthropological Quarterly, 85(3), 817-857. https://doi.org/10.1353/ anq.2012.0036.

Geertz, C. (1973). The Interpretation of Culture. New York: Basic Books.

Goodenough, W. H. (1994). Toward A Working Theory of Culture. In R. Borofsky (Ed.), Assessing Cultural Anthropology (pp. 262-275). New York: McGraw-Hill.

Harris, M. (1968). The Rise of Anthropological Theory: A History of Theories of Culture. New York: Thomas Y. Crowell.

Harris, M. (1979). Cultural Materialism: The Struggle for a Science of Culture. New York: Random House.

Koentjaraningrat. (1980). Pengantar llmu Antropologi. Jakarta: Aksara Baru.

Mahan, A. T. (1989). The Influence of Sea Power Upon History 1660-1793. Boston: Little Brown \& Company.
Manguin, P. Y. (2008). Welcome to Bumi Sriwijaya or the Building of a Provincial Identity in Contemporary Indonesia. Singapore: National University of Singapore.

Nilakanta-Sastri, K. A. (1949). History of Srivijaya. Madras: University of Madras.

Nurhayati. (2016). Melestarikan Budaya Seni Kain Jumputan Palembang. Kalpataru: Jurnal Sejarah dan Pembelajaran Sejarah, 2(1), 10-15. http://dx.doi.org/ 10.31851/kalpataru.v2i1.1312.

Orlove, B. (1980). Ecological Anthropology. Annual Review of Anthropology, 9(1), 235-273. https://doi.org/10.1146/annurev.an.09.100180.001315.

Pelly, U. (1975). Ara dan Perahu Bugisnya: Suatu Studi Pewarisan Keahlian Membikin Perahu Orang Bugis Kepada Anak dan Keturunannya. Ujung Pandang: PLPIIS Universitas Hasanuddin.

Rachmad, Y. (2017). Kerajaan Maritim Haru di Sumatera Timur 1477-1488. Jakarta: Direktorat Sejarah Kementerian Pendidikan dan Kebudayaan.

Reid, A. (2014). Asia Tenggara dalam Kurun Niaga 1450-1680 (Jilid 1). Jakarta: Yayasan Obor Indonesia.

Steward, J. H. (1955). Theory of Culture Change: The Methodology of Multilinear Evolution. Urbana: University of Illinois Press.

Vayda, A. P. \& Rappaport. (1968). Ecology, Cultural and Non-Cultural. In J. A. Clifton (Ed.), Introduction to Cultural Anthropology (pp. 476-491). Boston: Houghton Miffin.

Wallace, R. (2009). Kepulauan Nusantara. Jakarta: Komunitas Bambu.

White, L. A. (1949). The Science of Culture: A Study of Man and Civilization. New York: Grove Press, Inc. 
White, L. A. (1959). The Evolution of Culture:

The Development of Civilization to the Fall of Rome. New York: McCraw-Hill Book Company, Inc.

Zakharov, A. (2009). Constructing the Polity of Srivijaya in the 7th-8th Centuries: The View According to the Inscriptions. University of Sydney.

Zuhdi, S. (2014). Nasionalisme, Laut dan Sejarah. Jakarta: Komunitas Bambu. 